Portland State University

PDXScholar

Fall 2021

\title{
Gender Deviants: Subverting Regulatory Power in Medical Institutions
}

Ursa Nuffer-Rodriguez Mx.

Portland State University

Follow this and additional works at: https://pdxscholar.library.pdx.edu/honorstheses

Part of the Ethics and Political Philosophy Commons, Feminist Philosophy Commons, Lesbian, Gay, Bisexual, and Transgender Studies Commons, and the Other Feminist, Gender, and Sexuality Studies Commons

Let us know how access to this document benefits you.

\section{Recommended Citation}

Nuffer-Rodriguez, Ursa Mx., "Gender Deviants: Subverting Regulatory Power in Medical Institutions" (2021). University Honors Theses. Paper 1148.

https://doi.org/10.15760/honors.1186

This Thesis is brought to you for free and open access. It has been accepted for inclusion in University Honors Theses by an authorized administrator of PDXScholar. Please contact us if we can make this document more accessible: pdxscholar@pdx.edu. 


\title{
Gender Deviants:
}

\section{Subverting Regulatory Power in Medical Institutions}

\author{
by \\ Ursa Nuffer-Rodriguez
}

An undergraduate honors thesis submitted in partial fulfillment of the requirements for

Bachelor of Arts

in

University Honors

and

Arts \& Letters

Thesis Adviser

Monica Mueller, Ph.D.

Portland State University 


\begin{abstract}
Medical and psychiatric institutions have a long history of regulating and pathologizing the bodies of non-normative individuals. The harmful normativity of these institutions is particularly salient for trans* people pursuing gender-affirming medical care, as popular media representations of trans* identity reinforce narratives of certainty and aspirations towards cisgender standards of corporeality which rarely map onto authentic narratives of trans*ness. For the gender deviant subject, who conceives of hirself beyond these hegemonic notions of identity, navigating these institutions often requires a false projection of identity that fits the standard narrative, simply as a means to an end. In doing so, the gender deviant subject manipulates the normativity of these medical and psychiatric institutions in order to stretch the boundaries of socially accepted identity, a mentality and way of being in the world which offers liberatory possibilities for coalition across non-normative identity groups who face subjugation by the dominant regulatory apparatus.
\end{abstract}

\title{
Introduction
}

For most of my teenage years, I had this recurring dream in which I took a knife to my own chest. The knife was dull, but I'd saw away in desperation, trying frantically to carve flatness from the mounds of flesh that had grown over my ribcage in puberty. I'd wake with a start, frustrated tears glittering in my eyes. I took to wearing giant hoodies and loose-fitting clothes, underneath which I'd suffocate myself with tight sports bras and chest binders to create an illusion of flatness that might obscure my natal gender assignment of "female". I cut my hair short and shopped exclusively in the men's section, compensating for the parts of myself that felt 
immutably "feminine" with masculinity in an attempt to approximate the enigmatic feeling of gender-ambiguity that I felt inside.

Dreams of a different body are not uncommon amongst transgender, non-binary and other gender variant (trans*) individuals. These dreams are usually manifestations of gender dysphoria: a visceral feeling of misalignment between one's body—as it is gendered and perceived by onlookers - and one's internal feeling of gender and bodily being. This disconnect is painful and puts trans* people at a higher risk of suicide (Wiepjes et al. 2017). Coupled with disproportionately high rates of employment discrimination, intimate partner and domestic violence, poverty, and homelessness, (HRC 2020) it is undeniable that trans* people in the United States live with the odds stacked against their health and happiness at every turn. Despite this, gender-affirming health care-including puberty suppression therapies, hormone replacement therapies, and various surgeries - has been shown again and again to increase quality of life for trans* people (Baker et al. 2021). These medical interventions, however, are highly regulated within the medical industry. Accessing these gender- and life-affirming treatments requires navigating a hostile and bureaucratic system which legitimizes the trans* subject's pursuit of bodily comfort through standards shaped by media representations of trans* identity that collapse the spectrum of trans* experience into a flat, monolithic narrative.

The dominant portrayal of trans* identity follows a linear journey from one binary gender to another. Many of the trans* people we see in popular media have transitioned into flawless depictions of masculinity or femininity and recount their coming out as an unveiling of certainty: they've always known exactly who they are. This narrative can be seen, both explicitly and implicitly, throughout popular culture. Transgender icons like writer/producer Janet Mock and actor/model/artist Chella Man both situate their discovery that they are something other than the 
gender they were assigned at birth in early childhood. Actor Elliot Page, who recently came out to the world as transgender, coupled his coming out with a short haircut and a perfectly sculped masculinized chest. In all these cases, a narrative of linear progress, cisgender aligned perfection, and certainty prevails.

This depiction falls short of representing the broader spectrum of trans* experience. Not all trans* people know from a young age that they are not their assigned gender and coming out doesn't always mean the start of a linear journey from one gender archetype to another, especially when navigating compounding oppressions. Particularly for non-binary, genderqueer, and other gender-expansive individuals, these narratives are far from sufficient. Nevertheless, the dominant narrative of certainty in popular culture converges with medical standards of care to reinforce certainty as a legitimizing force for trans* identity within medical hegemony. The disconnect between standards of trans*ness and lived experiences of trans*ness creates a divide that must be negotiated by people who seek medical care. It is also well documented that transgender people overwhelmingly experience mental illness: people with a diagnosis of gender dysphoria overwhelmingly have pre- and co-existing mental conditions (Nahata et. al 2017) and denial of gender-affirming care on the basis of these conditions is a well-worn tale within the trans community. What emerges for trans* people is an urgency to prove to medical providers that one is both "well enough" and "trans* enough" to be worthy of care, even if it means conforming to an inauthentic narrative. For a population already at higher risk of physical violence, navigating these complex and often hostile institutions creates additional psychic stress, which, coupled with the violence of a transphobic society, makes the question of access to gender-affirming medical care a question of life or death. 
Navigating medical and psychiatric institutions whose standards of trans* identity are predicated on false narratives of certainty, linearity, and cisgender standards of corporeality as a non-normative subject—named the gender deviant—requires a slippery, trickster mentality of (dis)identification with these dominant narratives which, when assessed through a broader lens critical of socially constructed difference, offers liberatory possibilities for survival and coalition across oppressed groups. In order to explore this phenomenon, I will begin by outlining the many layers of influence that shape trans* subjectivity, then I will illuminate the problem of medicalized normativity by charting the role of language in the categorization, regulation, and domination of non-normative bodies. I will demonstrate how the process of psychoanalysis in the bureaucracy of gender-affirming care is shaped by dominant narratives of certainty and cisgender corporeality, revealing the obstacles negotiated by the gender deviant subject. By exploring the paradoxical relationship between divergent and dominant identity, I will reveal the modes of (dis)identification that allow the gender deviant subject to both survive within and play with normative identity. This mentality, I conclude, offers new ways of being which create greater possibilities for liberation from the regulatory apparatuses which limit the autonomy of all nonnormative subjects.

\section{On Precision of Language}

When discussing issues of gender, power, and identity it is important to clarify the use of certain terms. Queer theorist and historian Susan Stryker (2017) employs the term transgender to refer to people who "move away from their birth-assigned gender... because they feel strongly that they properly belong to another gender, [while] others want to strike out towards... some new space not yet clearly defined or concretely occupied." Transgender, she writes, is "the 
movement across a socially imposed boundary away from an unchosen starting place," (17-18). I find that this definition of transgender aligns with how I choose to employ the term here.

Still, "transgender" alone doesn't fully encompass the experiences represented in this paper. Therefore, I'd like to build upon this term by drawing from Avery Tompkins' (2014) definition of the asterisk. Originating in internet search structure, the asterisk tells the search engine to show results for the typed text plus any additional characters. Such an origin offers an expansion of the term trans beyond the definitional limitations of transgender or transsexual. As Tomkins explains, the asterisk operates on many levels: as a stand-in for a list of identities, as an indication of deeper meaning, and/or as an invitation for further inquiry (27). Though the inquiry that follows often focuses on trans* people who have departed from their birth-assigned gender and individuals who pursue medical intervention in their journey towards gender confirmationwho may more accurately be described as "transsexuals"- I choose to employ trans* instead as a way of broadening the category. Additionally, the example of trans* people and medical intervention functions here as a single example of an institutional power struggle that manifests in different forms for many different people, not all of whom may be active in an arena of gender scrutiny. The asterisk gestures towards this ambiguity.

The word "transition" is the popular term used to describe medical interventions taken by trans* people, but I prefer to use the term "gender affirmation" or "gender-affirming care" for a few reasons. Primarily, the latter phrases have no implication of linear movement from one gender to another; rather, they gesture towards an ever-unfolding process of self-actualization. Not all people who choose medical interventions consider themselves "transgender" or "transsexual," so "gender affirmation" becomes a broader term that shifts the focus from these 
identity labels to the sense of (gendered) self and the process of aligning the physical form with that sense, whether it aligns with the person's natal gender assignment or not.

At times it may seem that I position the "gender deviants" of this paper in opposition to cisgender ${ }^{1}$ people. While the term "gender deviant" is invoked here most often in the context of trans* subjectivity, the analysis of gender deviants in relation to medical and psychiatric institutions has implications for deviants of a broader variety, as well as broader power structures. The assumption that all trans* people have non-normative bodies and that all cisgender people have normative bodies is complicated on multiple levels by the non-normative (but often cisgender) bodies of butch lesbians, neurodivergent people, fat people, disabled and chronically ill people, and many poor people of color. These subjectivities place the individual outside of the white, heterosexual, middle-class, straight sized ${ }^{2}$, and able-bodied archetype for which medical and psychiatric institutions are built to serve. Their non-normative corporealities are pathologized, and they often face discrimination or neglect in their pursuit of medical care.

Similarly, the gender deviant is an individual who does not fit the normative archetype. Resistance to this archetype, however, is a conscious act. The gender deviant is aware of the social, cultural, political, economic, and linguistic forces that shape identity formation, and the gender deviant pushes back on these forces, stretching language and ideas to their limits in order to expand our understanding of bodily possibility.

Throughout this project, I refer to the gender deviant through the use of the genderneutral pronouns sie/hir, which are pronounced like "see" and "hear." While the more widely accepted gender-neutral pronouns, they/them, may also be appropriate in this instance, I choose

\footnotetext{
${ }^{1}$ Cisgender refers to individuals whose gender identity aligns completely with the gender they were assigned at birth.

2 While there are many valid critiques of the term "straight size," which is meant to contrast the term "plus size," I was not able to identify a viable alternative.
} 
the sie/hir pronouns purposefully. In recent years, the singular "they" has risen in prominence among popular discourse. In 2019, Merriam-Webster dubbed the singular "they" the word of the year, as a public act of legitimization for non-binary and genderqueer English speakers, many of whom were using this pronoun long before it received public approval. While this broader awareness and acceptance of they/them pronouns has made navigating daily life simpler for many trans* subjects, it also indicates a shift of the singular "they" from a place of marginalized deviance to mainstream acceptability.

Therefore, the singular they pronoun, while often accurate for describing individuals whose identity does not fit neatly within the categories of "man" or "woman," fails to accurately encapsulate the boundary-manipulating, norm-challenging nature of the gender deviant subject. The sie/hir pronouns, which operate within normative grammar while simultaneously resisting its conventions, invites a reevaluation of the limits of socially accepted language in a way the singular "they" pronoun set, by nature of its recent assimilation into normative grammar, cannot.

\section{Layers of (Gender) Identity Formation}

For many individuals whose sense of self is not threatened by their natal gender assignment, the question of gender is peripheral, if considered at all. The disconnect between body and mind experienced by many trans* people makes this question of gender an explicit one. The trans* experience, then, illuminates the many layers of meaning that shape our understanding of gender identity. Discerning between an internal felt sense and externally projected sense of gender is one such delineation that the trans* experience offers, and socially constructed identity adds further complexity. 
Gayle Salamon's landmark book Assuming a Body: Transgender and the Rhetorics of Materiality (2010) operates at the intersection of phenomenology, transgender studies, and feminist philosophy. One of Salamon's primary explorations is the social construction of gender. The central claim of social construction is the conviction that how we understand and use our bodies, all the imaginable possibilities of our bodies, and how we conceptualize ourselves in relation to our bodies is structured by the cultural standards and histories of how bodies have been socially understood (76-77). Scholars in transgender studies have largely rejected this constructionist theory of gender in favor of an essentialist understanding of gender. In the wake of Judith Butler's Gender Trouble many trans* people rejected Butler's theory of gender performativity, which posits that gender is externally imposed through cultural rules and regulations onto the individual who unconsciously performs them, asserting instead that gender is a deep-seeded internal feeling. Extrapolating from the work of trans* theorist Jamison Green, Salamon describes the felt sense of gender as such:

...[T]he felt sense of the body delivers a certainty about identity, and though that felt sense might arise from a complicated nexus of body and psyche, the feeling itself is described as simple - the conviction that one is either a man or a woman - and as powerful and incontestable evidence of a coherent identity. Yet this feeling is unlocatable (it does not arise from or correspond to the morphology of the body) and is incontestable (it is not subject to question or doubt but presents itself as a "natural" fact). The felt sense of identity can, by virtue of its unlocatability, be said to arrive from elsewhere; the embodied subject can neither control nor reform it. He cannot name its origin or dispute what it asserts; he can only submit to it. (Salamon 2010, 83) 
Some trans* scholars assert that rather than being externally projected, gender is an inalienable truth of the body and mind. This conceptualization of gender orients itself as opposition to the theory of socially constructed gender. Nevertheless, Salamon suggests that this dichotomy between gender as a social construct and gender as an internal feeling is false. As a reconciliation of this dichotomy, she underscores that in claiming an innate sense of being 'male' or 'female,' we must recognize that 'male' and 'female' are social categories, and "the very fact that an internal conviction can deliver such a powerful certainty about one's individual sense of belonging to, or being alienated from, either category attest to the inseparability of one's own experience of gender and the larger social classifications that determine it," (82-83). Salamon reconciles the constructionist/essentialist dichotomy through a "both/and" approach, offering that gender can be both an internal sense of individual self and a matrix of power acted upon the individual. However, in doing so, she returns to social construction as the ultimate force of gender identity, implying that felt sense outside of socially constructed gender is improbable, if not impossible.

These influential forces - the felt sense (personal) and the social constructions (cultural) of gender-shape how individuals navigate the world as gendered subjects. They overlay onto one another through a person's upbringing, forming a composite that a person comes to call their "gender." For many, this is a process that happens unconsciously, but for trans* and gender deviant subjects, this is a conscious process of negotiating social conditioning, gender archetypes, and the subject's own felt sense of gender. An additional layer of influence, the influence of scientific discourse, is equally important (though often nominally absent) from this formation of identity. Scientific categorization, which heralds itself as immovably objective, is in fact another tool shaped by cultural and political motives to further the agendas of the powerful. 


\section{Categorization and Domination}

Language has long been a tool of regulation. This can be seen across time and space: from the colonial history of the US, where boarding schools isolated Indigenous children from their cultures and life ways by banning their native tongues in favor of English, to Foucault's (1978) analysis of emerging discourses around sex in eighteenth-century Europe, to Sommerville's (2000) work illuminating the link between scientific racism and the homosexual body in nineteenth century US medical institutions.

One project within History of Sexuality (Foucault 1978) is charting the emergence of language around sex over time. In response to the proliferation of sexual variance in rural, working-class Europe, sex became an object of discussion in academic and scientific discourse, "as if in order to gain mastery over it in reality, it [was first] necessary to subjugate it at the level of language," (17). Through the eighteenth-century and beyond, there was an explosion of discourse around sex, which created the conditions for defining and then regulating sexual deviance. Foucault outlines the way bodies become regulated through discourse: bodily realities are defined through the language of scientific discourse; through the authority wielded by that discourse and their affiliated institutions, 'rules' emerge around who is what and why. These rules go on to shape social norms, which dictate to society whose sexual practices are "natural" or "normal" and whose are "perverse." While Foucault explores this matrix of power/knowledge through the lens of sex, the regulatory powers of discourse can be seen across nearly every category of difference.

Consider the following example from Siobhan Sommerville's (2000) interrogation of scientific racism and the emergence of categories of race and sexuality in the United States. The 
now-debunked science of comparative anatomy asserted in the nineteenth century that certain physical features such as skin, facial features, skull size, brain mass, and genitalia, were distinct markers of racial difference and correlated with intelligence and behavior. This assertion was embraced unquestioningly, which is unsurprising given a social climate that can be aptly characterized by the contemporaneous Plessy v. Ferguson "separate but equal" declaration, Jim Crow and antimiscegenation laws, and widespread racial violence. Reflected here is a preoccupation, both in science and in popular culture, with defining all bodies as either "black" or "white."

Drawing from this same urgency for categorization, the discipline of sexology underwent a similar project defining the boundaries of sex and sexual deviance. Prior to this project, homosexuality was regarded as individual sex acts which might characterize a person as sexually "inverted," but did not constitute a homosexual identity in the way we think of it today. Though sexologists largely failed to identify somatic indicators of "inversion", physical examinations remained common, following the logic of biological determinism which asserted that, in the words of paleontologist Edwards Drinker Cope, "every peculiarity of the body has probably some corresponding significance in the mind," (Cope cited in Sommerville 2000). Sommerville illuminates how these discourses of categorization then became weaponized: "Supported by the cultural authority of an ostensibly objective scientific method," he explains, "these readings of the body became a powerful instrument for those seeking to justify the economic and political disenfranchisement of various racial groups within systems of slavery and colonialism," (Sommerville 2000, 250). Analogously, normative and non-normative sexuality became reified through comparative anatomy and sexology, leading to the justification of violence through techniques such as conversion therapy. 
Both examples outlined by Sommerville indicate a powerful relationship between scientific discourse, cultural normativity, and the regulation of bodies. We can see how social conditions shape scientific discourse, and how scientific discourse also shapes social conditions. Science, whose assertion of authority is largely contingent on its claim to objectivity, is revealed to be malleable, subjective to the social conditions under which it is performed. Such an analysis shakes the foundation of scientific discourse and its assumed mastery.

\section{Psychoanalysis and Autonomy}

The institutions of medical and psychiatric care assert authority over human wellness. Certainty, as it is constructed by the narratives of identity formation that proliferate in popular media, becomes a measure of wellness that clashes with authenticity in the arena of gender affirming care. Foucault's critiques of psychoanalysis serve as an apt framework for illustrating the tensions between certainty and authenticity for gender-diverse populations. The central frustration for Foucault is the normalization impulse in psychotherapy: the objective of psychoanalysis is to assimilate subjects into the existing social order, was a way to "alleviate the effects of repression" experienced by the subject who fails to function properly under the status quo (Foucault 1978, 129). Ultimately, this model of psychoanalysis does nothing to address the social and material conditions that cause subjects to suffer (and seek psychotherapy) and instead views the 'problem' of the subject's distress as internal and individual, rather than external and systemic.

Gender affirming care for trans* people serves as a particularly salient example of Foucault's critique. To illustrate, let's consider the example of hormone replacement therapy (HRT). In order to be approved for HRT by most health insurance companies and hormone- 
prescribing doctors, the trans* subject must undergo a rigorous, multi-session assessment by a psychotherapist to receive a letter of support in compliance with the World Professional Association for Transgender Health (WPATH) Standards of Care. During the assessment, the therapist must determine three main objectives: that the subject fits the criteria for Gender Dysphoria, understands the risks and limitations of HRT, and is mentally capable of giving informed consent (WPATH 2012, 26). In order to fit the criteria for Gender Dysphoria, one must not only prove a "marked incongruence" between the felt sense of gender and the natal assigned gender, but also display "clinically significant distress or impairment in social, occupational, or other important areas of functioning," (APA 2013, 459). These standards are intended to mitigate regret amongst individuals who pursue medical intervention, but when this intention intersects with the hegemonic narratives of trans* identity formation, the psychoanalytical process becomes paternalistic at best, and coercive at worst. According to this model, the 'problem' for the trans* subject is not the limiting conditions of a transphobic society, nor the oppressively rigid social conditioning based on natal gender assignment, rather their internal dysphoric experience and the distress of moving through the world in a body incongruent with their felt sense of gender. With the felt sense pathologized in this way, HRT, or any other form of medical intervention, is then offered to alleviate the suffering of a gender dysphoric individual by conforming their body to a cisgender standard.

Not every trans* individual who passes through a psychotherapist's office in pursuit of gender affirming care wishes to conform to a cisgender standard, and this is where legitimizing forces stands in opposition to authentic narratives. The popular representations of transgender people show linear journeys from cisgender-aligned femininity to masculinity (or vice-versa), but for gender deviant trans* people, this narrative does not align. Nevertheless, psychotherapy is 
a necessary step in navigating the bureaucracy of gender affirming care, so gender deviant trans* people must find ways to conform to the narrative.

The gender deviant, who feels confined by the gendered assumptions projected in accordance with hir physical anatomy, seeks self-actualization through gender-affirming medical intervention. In order to access these interventions, however, the gender deviant must defy hir authentic narrative of identity in order to appease the standards of certainty and cisgender corporeality that act as legitimizing forces within the psychoanalytical process. If sie succeeds, sie is accepted into the fold of the medical institution and can pursue bodily autonomy, though only so long as the journey remains intelligible to the medical practitioners overseeing the process. Thus ensues a paradox of autonomy wherein the gender deviant, who views hirself as antithetical to the cisgender standard, pursues gender sovereignty outside of rigid categorization, but in doing so is still confined by the authority of scientific discourse.

Judith Butler's (2004) exploration of this paradox can be aptly summarized as the following: an individual strives for autonomy (say, to present themself the way they feel is aligned with a felt sense of self-gender or otherwise) but that autonomy, and even the individual's conception of what that autonomy might be, is limited by the conditions in which the individual is situated: cis/heteropatriarchy, settler colonialism, white supremacy, and neoliberal capitalism in the US. We're never fully unburdened by the constraints of those conditions, hence the paradox in thinking we might be autonomous individuals outside of them.

Yet still, people try. Trans* people push and play with the boundaries of gender; colonized people claim lifeways outside of settler-colonial structures; people of color are empowered despite white supremacy; disabled people form care networks that resist neoliberal capitalism. All are still constrained by their respective systems of power: trans* expression is 
limited by gendered conditioning, decolonial praxis is overwhelmingly taught in colonial languages, white supremacy limits people of color at every turn, and disabled people must still participate in capitalism or undertake the arduously bureaucratic task of proving they cannot. Of course, these people groups and oppressive forces overlap and intersect into a matrix of domination and resistance too complex to summarize in a few simple sentences. Occupying these oppositional positions poses a threat to the normative order, which leaves the individual vulnerable to violence as the status quo fights to be maintained.

This violence stems from an epistemic fragility that, when exposed, becomes volatile. Under a Puritanic US American morality, "for a life to count as a good life, it must return the debt of its life by taking on the direction promised as a social good, which means imagining one's futurity in terms of reaching certain points along a life course," (Ahmed 2006, 554). Most often this looks like finding a (heterosexual) spouse, acquiring a well-paying job, popping out a couple kids and retiring (if you're lucky) after half a century in the workforce. "Such points accumulate," Ahmed notes, "creating the impression of a straight line," (554). Deviating from this straight line threatens the "social good" of that line, and for individuals who have never known anything but that trajectory, deviation is threatening. This is how we see phenomena like the gay/trans panic defense, a legal defense which "asks a jury to find that a victim's sexual orientation or gender identity is to blame for the defendant's violent reaction, including murder," (Holden 2019). Murder justified by simple deviation from normative identity points to the vulnerability of trans* bodies in a culture built on narrow understandings of selfhood. For the gender deviant, navigating this culture and its associated institutions of power is a perilous task that requires the gender deviant to find ways to protect hir genuine selfhood, all while negotiating standards of being that are incompatible with that very selfhood. 


\section{The Trickster Mentality}

The gender deviant subverts the dominant narratives of trans* identity formation through a trickster mentality that acts as psychic armor when navigating medical institutions and a society preoccupied with the categorization of everything and everyone. This mentality can be described in three distinct and interrelated ways: disidentification as survival, disidentification as

play, and mestiza consciousness. By approaching the trickster mentality from each vantage point, I will demonstrate how the trickster mentality works to protect the gender deviant, allowing hir to manipulate the standards of legitimacy as a means of attaining bodily autonomy.

\section{Disidentification(s)}

José Esteban Muñoz (1999) first theorized disidentifications out of the intersections of performance studies, queer of color theory, and critical Black and Latinx feminist political discourse. Disidentification is a theory that is purposefully ambiguous: while one can name many definitions, disidentification is itself resistant to the constraints of definition. To disidentify is to simultaneously deviate and conform: it is a way of operating within a system as a means of dismantling it. To disidentify is to both identity and not-identify: it is the act of twisting categories and definitions beyond their reified walls, to make boundaries that were once solid, porous. Disidentification is a mechanism of survival, particularly for queer and trans* people of color who must conform to white supremacist hegemony and cis-heteropatriarchal norms but have no desire to assimilate and/or actively wish to resist. 


\section{Disidentification as survival}

As a survival technique, disidentification is a powerful tool for the gender deviant trans* subject. Navigating medical and psychiatric institutions utilizing binary and linear narratives of certainty is often a psychologically damaging process for gender deviant trans* individuals. When authentic narratives do not map onto the hegemonic, legitimizing narrative of identity, the gender deviant is left with no choice but to present a disingenuous narrative that will grant hir access to the interventions sie seeks. The process of psychological assessment then becomes a dance between authenticity and intelligibility, resulting in a performance of certainty and linearity which is merely a means to an end.

The gender deviant trans* subject knows full well that the medical institution seeks to conform hir body to a cisgender standard. Though hir own narrative of gendered feeling is not aligned with the dominant narrative of trans* identity, conforming to the narrative is hir best and simplest path towards accessing life affirming —and often life saving — medical care. Sie recognizes the usefulness of the psychological assessment as a way of legitimizing (and therefore facilitating financial access via insurance) the discontinuity between body and mind characterized by gender dysphoria, but sie also knows that the assessment will only grant access so long as sie can make hirself intelligible, categorizable, and ultimately able to be normalized (in)to the dominant paradigm. This disidentificatory mentality acts as a buffer for the gender deviant subject that allows hir to navigate these medical and psychiatric institutions with less erosion of the individual's authentic narrative. With the armor of disidentification for survival, new opportunities open up for play with the dominant identity schema. 


\section{Disidentification as play}

The gender deviant subject knows hirself to be enigmatic. The existing monikers of identity fail to encapsulate the essence of hir felt sense of self. Nevertheless, the gender deviant subject, if we are to assume sie is a resident of the US, lives under the conditions of white supremacy, cis-heteropatriarchy, and neoliberal capitalism. Under these conditions, categorization is law, and identity is a site of commodification and organization. Those who are uncategorizable threaten the social order, and such threats are not taken kindly. So once again, the gender deviant subject must categorize hirself as a means of survival, but in doing so, invites a manipulation and dissolving of the very labels sie chooses to assert.

In this way, disidentification becomes a site of identity play. In a conversation about visibility and discrimination I may refer to myself a gay man to my cis male coworker, but this phrase utterly fails to represent me; I am only a man insofar as I am assumed to be so by the cisgender onlooker based on my deep voice and flat chest, and only gay in the broadest, most general sense of a gender-traversing erotics of similarity (Salamon 2010). I may more aptly, but still imperfectly, be described as a dyke-faggot-futch, an undgenderable and transsexualized body, a jota/joto indeterminable ${ }^{3}$. Asserting this web of signifiers may only leave someone with more questions than answers, so when I don't wish to entertain such questions, I fall back on the labels that sit comfortably on another's tongue: "non-binary," "trans-masculine," "pansexual" and "queer." By disidentifying with identity labels, I both acknowledge the limitations of language's ability to encapsulate the essence of my own felt sense, and simultaneously acknowledge the necessity of identifiers for navigating a society preoccupied with the

\footnotetext{
${ }^{3}$ Translating from Spanish to mean "undeterminable queer(feminine/masculine, pejorative.)"
} 
categorization of everything and everyone. Doing this disidentification with playfulness is my surest means of both physical and psychic survival.

\section{Mestiza Consciousness}

Yielding to the pressures of cis-heteropatriarchal categorization as a means of survival and/or identity play leads to a myriad of linguistic and cultural contradictions. These contradictions reveal the instability of categorization, which gives way to an epistemic anxiety wrought with intolerance. To begin imagining sites of resistance to dominant forces of identity construction, one might find herself on a journey into the borderlands. For borderlands theorist Gloria Anzaldúa (2012), the borderland is a physical, metaphorical, spiritual and linguistic space between dichotomous poles where resistance is born. It is the liminal space where people living between labels, between cultures, between races, or between nation-state boundaries reside. It is a site of psychic restlessness, but what is born of these physical, mental, cultural and linguistic borderlands is a new form of consciousness that pushes the boundaries of our ways of being. This is the mestiza consciousness, a state of mind that allows us to traverse dichotomies and see the harmony in contradiction. In her own words, Anzaldúa describes the revolutionary possibilities of this mindset as such:

The work of mestiza consciousness is to break down the subject-object duality that keeps her a prisoner and to show in the flesh and through the images in her work how duality is transcended. The answer to the problem between the white race and the colored, between males and females, lies in healing the split that originates in the very foundation of our lives, our cultures, our languages, our thoughts, (Anzaldúa 2012, 102). 
While the mestiza consciousness holds liberatory possibilities for healing these splits, it cannot be achieved by the mestiza alone. It cannot be achieved by the gender deviant alone, nor the woman of color, the disabled or the proletariat alone. Healing the split between dichotomous and binary positions requires a coming together of both and all sides. In the case of gender-affirming care, this necessitates an erosion of the divide between psychotherapist and the trans* subject.

\section{Towards Coalition}

There are surely exceptions to the rule of normative identity in gender-affirming care; there are surely psychotherapists and physicians open to accommodating narratives that deviate from the expected trans* narrative of linearity, certainty, and cisgender corporeality. However, it is undeniable that these individuals are exceptions to the rule, not the rule itself. If the goal of gender-affirming medical care is truly to facilitate "safe and effective pathways to achieving lasting personal comfort" (WPATH 2012, 1), then learning from and adopting the playfulness of the gender deviant is the best way to facilitate a relationship grounded in authenticity and ultimately provide more comprehensive and affirming medical care.

It is this playfulness that allows the gender deviant to relieve the stress of navigating a hostile institution. This navigation of the medical system is not in itself play, however it is "the attitude that carries [the gender deviant] through the activity, a playful activity, turns the activity into play. [The navigation] has no rules, though it is certainly intentional activity and [the gender deviant] understand[s] what [sie is] doing," (Lugones 1987, 16, original emphasis). The gender deviant already moves through the world with a playful attitude, but an adoption of this playfulness on the part of the medical institution — particularly the psychotherapist—would go much farther in facilitating an authentic interaction between subject and therapist because "the 
playfulness that gives meaning to our activity includes uncertainty, but in this case the uncertainty is an openness to surprise," (Lugones 1987, 16, original emphasis). Being open to surprise means acknowledging that the therapist/subject relationship is not hierarchical, but a relationship between equals with unequal access. Openness to surprise invites curiosity and a willingness to learn, a willingness to bear witness without fully understanding, to practice respect without demanding the subject make hirself transparent.

Such a transformation has liberatory possibilities beyond questions of gender and genderaffirming care. The dominating narratives that shape medical and psychiatric practices are harmful to all non-normative bodies, not simply the gender deviant. But the gender deviant, who stands in bold opposition to these narratives, who chooses to remain unintelligible even as the powers that be require hir adherence to discrete categories, offers a point of departure for destabilizing these very systems of categorization. Only by allowing one another to remain opaque can we begin unraveling the regulatory powers of cis-heteropatriarchy, toxic masculinity, white supremacy and neoliberal capitalism that work to categorize the uncategorizable, ultimately to the detriment of us all. However, coalescing around the shared struggle of categorical and medicalized oppression is not always a simple task. The discrimination faced by the gender deviant in medical institutions will be different from that of the woman of color, which will be different from that of the disabled person, which will be different from that of the person on Medicaid, all of which will be different from that of the non-English speaking immigrant. Though all may share a vested interest in building a coalition to dismantle the regulatory apparatus, entering a coalitional space together requires juggling the multiple positions of privilege and oppression that each individual occupies. 
The problem, argues María Lugones (2006), with current theorizing of coalition formation, is that it assumes that all paths to the liminal, coalitional space are the same. It assumes that when we get there, we will all miraculously understand one another, all speak the same language of liberation- Lugones knows this is not true. As a remedy, she offers a form of complex communication that takes three modes simultaneously: an oppositional address to the oppressor, an acknowledgement of the individual struggles faced by the oppressed, and a call to coalitional action across oppressed groups. This form of communication allows us to enter a coalitional space authentically, without reducing our individual needs and experiences into a singular, universally intelligible monologue. We need not become transparent to one another, because "complex communication thrives on recognition of opacity and on reading opacity, not through assimilating the text of others to our own," (Lugones 2006, 84). Complex communication also requires its counterpart: transgressive hearing. Transgressive hearing, as Lugones explains, allows us to recognize one another as occupying individual liminal sites, and learning to read their words, gestures, and ways of being outside of the dominant paradigm (79). By shifting into a mode of complex communication and transgressive hearing, we can band together and begin the work of interrogating and dismantling the regulatory powers of domination that persist in medical and psychiatric institutions.

\section{Conclusion}

Nearly a decade after that dream of a dull knife first surfaced in my subconscious, I went under the very real and very sharp knife of a skilled surgeon who performed a double mastectomy, leaving rolling plains where there had once been mountains. When I looked in the mirror for the first time after surgery, unveiling a delicately reconstructed chest with two drains 
dangling from holes near my armpits, I expected to be overwhelmed with emotion. To tell you that I was would defy my own narrative in favor of the dominant one; but when I looked in the mirror, the moment was wholly unremarkable. I felt normal, like this was the way I had always been.

When I tell you I've been undergoing hormone replacement therapy for two years, or that I've had most of my breast tissue removed, or that my hair is the longest it's been in over 8 years, I am not telling you the story of my "gender." I'm showing you how I learned to forge my own vision of masculinity, to reject colonial standards of beauty and embrace my ancestral legacy of sovereign resilience. I'm sharing how, in my recovery from surgery, I came face-toface with my own fatphobia and ableism and began the uncomfortable work of learning to honor the needs and limitations of my body, as well as others'. I'm telling you about how I learned to fall in love with food again, how I learned to love the rough texture of pubescent skin. I'm divulging the erotics of scar tissue, illuminating the sacred ritual of self-injection.

This is not a story of gender; it is a story of relationality. I'm telling you about my journey home to this body, about how I built bridges between different facets of myself to create synthesis where there had always been discord. It is not a story that is immediately comprehensible to everyone, and it doesn't have to be. The story of my own corporeal journey is meant only to invite you to look inwards towards your own. How do you relate to your own body, how does your body relate to the world? How much of that relationship comes from within you, and how much of it has been prescribed to you by the dominant narratives of our culture? How might an inspection of your own identity narrative connect you to your own gender deviance? 


\section{Works Cited}

Ahmed, Sara. 2006. “Orientations: Toward a Queer Phenomenology.” GLQ: A Journal of Lesbian and Gay Studies 12 (4): 543-74.

American Psychiatric Association (APA). 2013. "Gender Dysphoria.” In Diagnostic and statistical manual of mental disorders: DSM-5, 451-59. Arlington, VA: American Psychiatric Association.

Anzaldúa, Gloria. 2012. “La Conciencia de La Mestiza / Towards a New Consciousness.” In Borderlands / La Frontera, 4th ed. San Francisco: Aunt Lute Books.

Baker, Kellan E, Lisa M Wilson, Ritu Sharma, Vadim Dukhanin, Kristen McArthur, and Karen A Robinson. 2021. "Hormone Therapy, Mental Health, and Quality of Life Among Transgender People: A Systematic Review.” Journal of the Endocrine Society 5 (4): bvab011. https://doi.org/10.1210/jendso/bvab011.

Butler, Judith. 2004. Undoing Gender. New York; London: Routledge.

Foucault, Michel. 1978. The History of Sexuality, Volume 1: An Introduction. New York:

Human Rights Foundation (HRC). 2020. "Dismantling a Culture of Violence.” https://reports.hrc.org/dismantling-a-culture-ofviolence?.ga=2.128618124.1205861906.1637252523-859594849.1637252523.

Holden, Alexandra. 2019. “The Gay/Trans Panic Defense: What It Is, and How to End It.” American Bar Association (op ed). Summer 2019. https://www.americanbar.org/groups/crsj/publications/member-features/gay-trans-panicdefense/.

Lugones, María. 1987. “Playfulness, 'World'-Travelling, and Loving Perception.” Hypatia 2 (2): 3-19. —. 2006. “On Complex Communication.” Hypatia 21 (3): 75-85. 
Nahata, L., Quinn, G. P., Caltabellotta, N. M., \& Tishelman, A. C. (2017). Mental Health Concerns and Insurance Denials Among Transgender Adolescents. LGBT Health, 4(3), 188-193. doi:10.1089/lgbt.2016.0151

Muñoz, José Esteban. 1999. Disidentifications: Queers of Color and the Performance of Politics. University of Minnesota Press. https://b-ok.cc/book/3364841/875cea.

Poteat, Tonia, German, Daniel, \& Kerrigan, Deanna (2013). Managing uncertainty: A grounded theory of stigma in transgender health care encounters. Social Science \& Medicine, 84, 22-29. doi:10.1016/j.socscimed.2013.02.019

Salamon, Gayle. 2010. "Boys of the Lex: Transgender and Social Construction.” In Assuming a Body: Transgender and Rhetorics of Materiality, 83-107. Columbia University Press.

Stryker, Susan. 2017. “Context, Concepts, and Terms.” In Transgender History, second. Seal Press.

Somerville, Siobhan. 2000. "Scientific Racism and the Emergence of the Homosexual Body." Journal of the History of Sexuality 5, no. 2: 243-66. www.jstor.org/stable/3704199.

Tompkins, Avery. 2014. “Asterisk.” TSQ: Transgender Studies Quarterly 1 (1-2): 26-27. https://doi.org/10.1215/23289252-2399497.

Wiepjes, C. M., M. den Heijer, M. A. Bremmer, N. M. Nota, C. J. M. de Blok, B. J. G. Coumou, and T. D. Steensma. 2020. “Trends in Suicide Death Risk in Transgender People: Results from the Amsterdam Cohort of Gender Dysphoria Study (1972-2017).” Acta Psychiatrica Scandinavica 141 (6): 486-91. https://doi.org/10.1111/acps.13164.

World Professional Association for Transgender Health (WPATH). 2012. Standards of Care for the Health of Transsexual, Transgender, and Gender Nonconforming People [ $7^{\text {th }}$ Version]. https://www.wpath.org/publications/soc 